\title{
The effect of remdesivir on selective biomarkers and its value in predicting the clinical outcome in patients with COVID-19
}

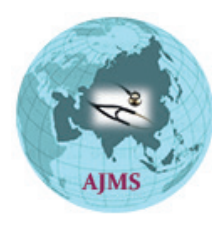

\author{
Sanjana Rai', Dyna Jones'2, Jayashankar Chinnappa Anjanappa ${ }^{3}$, \\ Venkata Bharat Kumar Pinnelli ${ }^{4}$, Eashwer Manpreeth ${ }^{5}$, \\ Seetha Venkata Sai Raghava Prashanthi ${ }^{6}$
}

${ }^{1}$ Associate Professor, ${ }^{2}$ Assistant Professor, ${ }^{3}$ Professor and Head, ${ }^{5,6}$ Junior Resident, Department of General Medicine, ${ }^{4}$ Professor, Department of Biochemistry, Vydehi Institute of Medical Sciences and Research Centre, Bengaluru, Karnataka, India

A B S T R A C T

Background: To the best of our knowledge, there have been no studies to evaluate the effect of remdesivir on inflammatory markers. Aims and Objectives: To study the effect of Remdesivir on Selective biomarkers namely C-Reactive Protein (CRP), Lactate Dehydrogenase (LDH), Serum Ferritin and D-dimer and their value in predicting the clinical outcome in patients with COVID -19 infection. Materials and Methods: This is a retrospective observational study including 102 laboratoryconfirmed COVID-19 patients of moderate and severe category who were subjected to complete blood count, liver function test, BUN, creatinine, C-reactive protein, lactate dehydrogenase, D-dimer, serum ferritin, ECG, and chest X-ray. The association was analyzed using independent sample t-test or Mann-Whitney U-test. Patients were divided into two groups. Both received corticosteroids and anticoagulants. Group A also received remdesivir. Results: Of the 102 patients, $90.2 \%$ of the patients in the non-remdesivir group and $94.1 \%$ in the remdesivir group were discharged. The mortality rate was $9.8 \%$ in the non-remdesivir group versus $5.9 \%$ in the remdesivir group $(P=0.71)$. There was no statistically significant difference in the decrease of the inflammatory markers overtime in both the groups, irrespective of whether they received remdesivir or not. Conclusion: High values of the inflammatory markers were seen at the time of admission. A 5 days course of remdesivir failed to demonstrate a statistically significant difference in the decrease in the levels of the inflammatory markers. However, we have observed a possible clinical benefit of remdesivir among patients with moderate and severe COVID-19 disease, as there was a trend toward better clinical outcomes. Further studies are needed to evaluate this therapeutic strategy.
http://nepjol.info/index.php/AJMS DOI: 10.3126/ajms.v12i12.39164 E-ISSN: 2091-0576 P-ISSN: 2467-9100

Copyright (c) 2021 Asian Journal of Medical Sciences

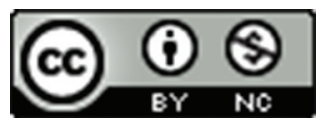

This work is licensed under a Creative Commons Attribution-NonCommercial 4.0 International License.

Key words: COVID-19 infection; C-reactive protein; D-Dimer; Ferritin; Inflammatory markers; Lactate dehydrogenase; Remdesivir

\section{INTRODUCTION}

The outbreak of COVID-19 has imposed a huge threat to global public health. ${ }^{1}$ The spectrum of the disease severity ranges from mild asymptomatic disease to pneumonia leading to acute respiratory distress syndrome, multiple organ dysfunction, and even death. ${ }^{1}$

The rapid viral replication of SARS-CoV-2 and destruction of cells stimulate the inflammatory response and recruit macrophages which release cytokines, chemokines that attract immune cells leading to cytokine storm, subsequent multiorgan dysfunction, and death. ${ }^{1}$

Remdesivir a nucleotide analog targets the viral RNAdependent RNA polymerase needed for the replication of SARS-CoV-2. ${ }^{2}$ Thus, inhibiting the viral replication it inhibits the inflammatory response, and improves the clinical outcome.

Hence, early administration of remdesivir might be crucial for ensuring an efficient treatment, decrease in mortality, and an early discharge. 
Furthermore, there is accumulating evidence that the inflammatory responses play a critical role in the progression of COVID-19. ${ }^{1,3-5}$ Hence, severe COVID-19 is associated with higher levels of inflammatory markers as compared to mild disease.

There have been no studies to evaluate the effect of remdesivir on inflammatory markers to the best of our knowledge.

Hence, this study has been undertaken to study the effect of remdesivir on selective biomarkers, namely, C-reactive protein (CRP), lactate dehydrogenase (LDH), serum ferritin, and $\mathrm{D}$-dimer and their value in predicting the clinical outcome in patients with COVID-19 infection.

\section{Aims and objectives}

To study the effect of remdesivir on selective biomarkers, namely, C-reactive protein (CRP), lactate dehydrogenase $(\mathrm{LDH})$, serum ferritin, and $\mathrm{D}$-dimer and their value in predicting the clinical outcome in patients with COVID-19 infection.

\section{MATERIALS AND METHODS}

This is a retrospective observational study, which was pre-approved by the Institutional Ethics Committee. It included 102 laboratory confirmed COVID-19 patients of moderate and severe category between the age group of 18 and 60 years by RT-PCR on nasopharyngeal swab between August 1, 2020, and October 30, 2020, admitted in the Department of General Medicine of Vydehi Institute of Medical Sciences and Research Centre.

A detailed history comprising demographic characteristics, presenting complaints, and comorbidities was recorded, the patients then were categorized as mild, moderate, and severe disease based on the clinical criteria according to the Karnataka Government guidelines of August 2020. Category B (moderate) patients were those who had the features of respiratory rate $24-30 / \mathrm{min}, \mathrm{SpO}_{2} 90-94 \%$ at room air. Category $\mathrm{C}$ (severe) patients were those who had the features of respiratory rate $>30 / \mathrm{min}, \mathrm{SpO}_{2}<90 \%$ at room air or $<94 \%$ with oxygen, acute respiratory distress syndrome, or septic shock. In addition to examination, all the patients were subjected to complete blood count using DXH-900 automated hematology analyzer with six part differentials, liver function test using Beckman Coulter Unicel DXC 800 Synchron Clinical system, blood urea nitrogen by urease UV method, creatinine by Jaffe's kinetic method, CRP by Nephelometry method, LDH by lactate to pyruvate method, D-dimer by latex immunoassay and serum ferritin levels by Clinical Laboratory Improvement
Amendments method, ECG, and chest X-ray. Both the groups received corticosteroids and anticoagulants. In addition, Group A received intravenous remdesivir (200 $\mathrm{mg}$ on day 1 followed by $100 \mathrm{mg}$ on days $2-5$ in single daily infusions) as per Karnataka Government Treatment protocol and Group B did not receive intravenous remdesivir. The patients excluded from the study were category A (mild) patients with respiratory rate $<24$ cycles $/ \mathrm{min}, \mathrm{SpO}_{2}>94 \%$ in room air; patients with pre-existing comorbidities, namely, chronic liver disease, chronic kidney disease, malignancy, thromboembolism, diabetes mellitus, hypertension, ischemic heart disease, chronic lung disease, sepsis, anemia, pregnant women, and children.

\section{Statistical analysis}

Statistical analysis was carried out for the laboratory confirmed moderate to severe COVID-19 patients.

The association was analyzed using independent sample t-test or Mann-Whitney U-test.

Microsoft Excel 2013 and Statistical Package for the Social Sciences Version 19.0 software were used for data entry and analysis.

$\mathrm{P}<0.05$ will be considered as statistically significant.

Informed consent has been waived off as it is a retrospective study.

\section{RESULTS}

In this study, we had a cohort of patients that did not receive remdesivir and those that did. The first 51 patients in each group were selected the non-remdesivir group (Group A) and remdesivir group (Group B) for the study.

The median age of patients was 42 years in Group A and 41 years in Group B with a majority of the patients being males, $80.4 \%$ in Group A and $76.5 \%$ in Group B (Table 1).

\begin{tabular}{|c|c|c|}
\hline \multirow[t]{2}{*}{ Variables } & \multicolumn{2}{|c|}{ Remdesivir N (\%) } \\
\hline & Not received & Received \\
\hline $\begin{array}{l}\left.\text { Age (Median } Q_{1}, Q_{3}\right) \\
\text { Gender }\end{array}$ & $42(35.55)$ & $41(33.50)$ \\
\hline Male & $41(80.4)$ & 39 (76.5) \\
\hline Female & $10(19.6)$ & $12(23.5)$ \\
\hline \multicolumn{3}{|l|}{ Severity } \\
\hline Moderate & $44(86.3)$ & $30(58.8)$ \\
\hline Severe & $7(13.7)$ & $21(4.2)$ \\
\hline \multicolumn{3}{|l|}{ Outcome } \\
\hline $\begin{array}{l}\text { Discharged with } \\
\text { government protocols }\end{array}$ & $46(90.2)$ & $48(94.1)$ \\
\hline Mortality & $5(9.8)$ & $3(5.9)$ \\
\hline
\end{tabular}


In the non-remdesivir group, $86.3 \%$ had moderate illness and $13.7 \%$ had severe illness. Whereas, in the remdesivir group, the patients with moderate and severe disease were $58.8 \%$ and $41.2 \%$, respectively $(\mathrm{P}=0.002)$ (Table 1).

\section{Correlation of inflammatory markers between the} groups (Table 2)

The inflammatory markers, namely, D-dimer, ferritin, $\mathrm{LDH}$, and CRP were serially monitored in all patients on day 1, day 3, and day 5 of hospital admission. These markers were seen to be higher at presentation (day 1) in the non-remdesivir group as compared to the remdesivir group (Table 2).

There was a significant decrease in the mean ferritin $(\mathrm{P}<0.001)$ and $\mathrm{LDH}(\mathrm{P}=0.001)$ values over these time points in both the groups, irrespective of whether they received remdesivir or not (Table 2).

There was no statistically significant difference in the decrease in the mean values of any of the inflammatory markers between the two groups (Table 2).

\section{Clinical outcome}

In our study, $90.2 \%$ of the patients in the non-remdesivir group and $94.1 \%$ in the remdesivir group were discharged. The mortality rate was $9.8 \%$ in the nonremdesivir group versus $5.9 \%$ in the remdesivir group. Fisher's exact test was performed to see the association between outcome and group. This difference was not found to be significant $(\mathrm{P}=0.71)$ (Table 1). There was a significant decrease in the mean ferritin $(\mathrm{P}<0.001)$ and $\mathrm{LDH}(\mathrm{P}=0.001)$ values overtime in both the groups, irrespective of whether they received remdesivir or not. A 5 days course of remdesivir failed to demonstrate a statistically significant difference in the decrease in the levels of the inflammatory markers.

\section{DISCUSSION}

In our study of 102 patients, it was observed that men had a significantly higher rate of hospitalization as compared to women which is in agreement with other studies done by Gomez et al., and Bischof et al.,

Our study also showed, $90.2 \%$ of the patients in the non-remdesivir group and $94.1 \%$ in the remdesivir group were discharged. The mortality rate was $9.8 \%$ in the nonremdesivir group versus $5.9 \%$ in the remdesivir group.

Our findings corresponded with the ACT'T-1 trial, which is an multinational study of 1062 patients where the patients were randomized in a 1:1 ratio to receive remdesivir or placebo showed that the recovery time among the remdesivir group was shortened by 5 days $(\mathrm{P}<0.001)$ and a lower mortality rate among the remdesivir group which was not statistically significant. ${ }^{8}$

Furthermore, a study by Mehta et al., showed mortality benefit with initiation of remdesivir $\leq 9$ days from symptom onset which reinforced the need for appropriately timed remdesivir in moderate-to-severe COVID-19.?

Our study showed high levels of inflammatory markers, namely, D-dimer, ferritin, LDH, and CRP among the patients who were categorized among the moderate and severe illness category on admission.

This was similar to results of a meta-analysis comprising 3962 patients done by Zeng et al., which showed higher levels of CRP, LDH, procalcitonin, and serum ferritin among the severe illness patients as compared to the mild illness patients. ${ }^{1}$

A meta-analysis by Ghahramani et al., also showed higher levels of inflammatory markers among the severe group versus non-severe group. ${ }^{10}$

\begin{tabular}{|c|c|c|c|c|c|c|}
\hline Variables & Group & Day 1 & Day 3 & Day 5 & $\begin{array}{c}\text { P value } \\
\text { (between groups) }\end{array}$ & $\begin{array}{c}\text { P value } \\
\text { (between time) }\end{array}$ \\
\hline D-dimer & $\begin{array}{l}\text { Remdesivir } \\
\text { Not received }\end{array}$ & $\begin{array}{c}1236.33 \pm 2089.19 \\
802.65 \pm 882.35\end{array}$ & $\begin{array}{l}1362.51 \pm 2358.57 \\
1189.80 \pm 1839.76\end{array}$ & $\begin{array}{l}1300.08 \pm 2165.98 \\
1211.63 \pm 1925.07\end{array}$ & 0.39 & 0.33 \\
\hline Ferritin & $\begin{array}{l}\text { Received } \\
\text { remdesivir } \\
\text { Not received } \\
\text { Received }\end{array}$ & $\begin{array}{l}742.76 \pm 459.95 \\
695.07 \pm 435.44\end{array}$ & $\begin{array}{l}726.63 \pm 407.52 \\
655.06 \pm 354.87\end{array}$ & $\begin{array}{l}679.28 \pm 311.11 \\
553.41 \pm 304.33\end{array}$ & 0.24 & $\begin{array}{c}0.001 \\
\text { Day } 1 \text { vs. Day 3: } 0.78 \\
\text { Day } 1 \text { vs. Day 5: } 0.002^{*} \\
\text { Day } 3 \text { vs. Day 5: } 0.005^{*}\end{array}$ \\
\hline LDH & $\begin{array}{l}\text { Remdesivir } \\
\text { Not received } \\
\text { Received }\end{array}$ & $\begin{array}{c}335.41 \pm 149.84 \\
316.90 \pm 87.87\end{array}$ & $\begin{array}{c}333.77 \pm 132.92 \\
314.33 \pm 82.36\end{array}$ & $\begin{array}{c}307.35 \pm 127.87 \\
280.12 \pm 73.10\end{array}$ & 0.24 & $\begin{array}{c}\text { 0.001* } \\
\text { Day } 1 \text { vs. Day 3: } 1 \\
\text { Day } 1 \text { vs. Day 5: } 0.001^{*} \\
\text { Day } 3 \text { vs. Day 5: } 0.008^{*}\end{array}$ \\
\hline CRP & $\begin{array}{l}\text { Remdesivir } \\
\text { Not received } \\
\text { Received }\end{array}$ & $\begin{array}{l}6.79 \pm 6.26 \\
5.98 \pm 4.54\end{array}$ & $\begin{array}{l}5.95 \pm 6.06 \\
4.81 \pm 4.63\end{array}$ & $\begin{array}{l}5.97 \pm 6.21 \\
3.98 \pm 5.32\end{array}$ & 0.11 & 0.05 \\
\hline
\end{tabular}


CRP, a hepatic protein which is regulated at the transcriptional level by the cytokine IL-6 and IL-1, is a reliable marker of inflammation. ${ }^{11}$ There is accumulating evidence that higher levels of CRP are associated with severe COVID-19 infection. ${ }^{12-14}$

Our study showed that patients with moderate and severe COVID-19 infection had high values of CRP in moderate and severe COVID-19 infection at the time of admission. However, there was no statistical difference in the reduction of the CRP values among the patients who received inj. remdesivir.

Our findings were similar to a study by Smilowitz which showed that higher levels of CRP were associated with critical illness and mortality in COVID-19 patients. $^{15}$

Similarly, a study of 131 patients showed persistently rising values of CRP was associated with higher levels of mortality among COVID-19 patients. $^{16}$

D-dimer, formed by the activation of the plasmin enzyme, indicates the presence of broken-down fibrin in the bloodstream and represents the activation of coagulation and fibrinolysis systems. ${ }^{17}$ Studies have indicated that higher levels of D-dimer were associated with more severe disease due to various reasons like increased levels of pro-inflammatory cytokines, thrombosis leading to venous thromboembolism and severe sepsis which leads to increased levels of plasminogen activator inhibitor 1 , and excessive fibrinolysis. ${ }^{18}$

Our study showed that patients with moderate and severe COVID-19 infection had high values of D-dimer at admission. However, there was no statistical difference in the reduction of the $\mathrm{D}$-dimer values among the patients who received inj. remdesivir.

Our findings were in agreement with a meta-analysis of 1807 patients done by Paliogiannis which revealed that higher D-dimer levels were associated with more severe COVID-19 infection as compared to non-severe infection. ${ }^{19}$

Similarly, a study done by Huang et al., on 676 revealed that a persisting increase in D-dimer levels was associated with higher incidence of mortality in COVID-19 patients. $^{20}$

$\mathrm{LDH}$, an intracellular enzyme, is found in cells in almost all organ systems, and it catalyzes the interconversion of pyruvate and lactate, with concomitant interconversion of $\mathrm{NADH}$ and $\mathrm{NAD}^{+} .{ }^{21}$ Isoenzyme 3 of $\mathrm{LDH}$ is present in lung tissue. Hence, greater levels of $\mathrm{LDH}$ are seen in patients with severe COVID-19 infection who have severe interstitial pneumonia, often evolving into acute respiratory distress syndrome. ${ }^{22}$

Our study showed that patients with moderate and severe COVID-19 infection had high values of LDH on admission. However, there was statistical decrease in the reduction of the $\mathrm{LDH}$ values among the patients irrespective who received inj. remdesivir.

Similarly, a study by Henry et al., showed that higher levels of S. LDH were associated with 6 times higher risk of developing more serious infection and 16 times increase in the odds of mortality. ${ }^{22}$

Furthermore, a study done by Martha on 10,399 showed a higher probability of worse outcomes in patients with COVID-19 infection. ${ }^{23}$

Ferritin in COVID-19 is characterized as an acute-phase reactant, as well as a mediator of immune dysregulation. Several complex feedback mechanisms between ferritin and cytokines exist in the control of pro-inflammatory and anti-inflammatory mediators. Cytokines induce the expression of ferritin. Furthermore, ferritin can induce the expression of pro- and anti-inflammatory cytokines. $^{24}$

Our study showed that patients with moderate and severe COVID-19 infection had high values of ferritin in COVID-19 infection. However, there was statistical decrease in the reduction of the serum ferritin values among the patients irrespective who received inj. remdesivir.

A study done by Bo Zhou on 20 patients of COVID-19 patients showed higher levels of serum ferritin among patients with severe disease. ${ }^{25}$

Similarly, a study by Onur et al., showed high values S. ferritin among the non-survivors. ${ }^{26}$

Hence, higher levels of serum ferritin can be associated with severe COVID-19 infection.

\section{Limitations of the study}

To begin with our study is a retrospective analysis. Furthermore, the duration of follow-up was relatively short (5 days). Following up on inflammatory markers for a week after completing the course of remdesivir could have shown a difference between the groups. Furthermore, there is inhomogeneity in the groups studied with higher number of severe cases in the remdesivir group. Finally, we were not able to get a statistical analysis in the remdesivir subgroup due to very few patients with severe disease in the non-remdesivir 
group. Probably looking at moderate and severe illness separately would be more conclusive.

\section{CONCLUSION}

High values of the inflammatory markers were seen among the moderate and severe illness patients at the time of admission. A 5 days course of remdesivir failed to demonstrate a statistically significant difference in the decrease of the levels of the inflammatory markers. However, we have observed a possible clinical benefit of remdesivir among patients with moderate and severe COVID-19 disease, as there was a trend toward better clinical outcome among the patients receiving remdesivir. Further studies are needed to evaluate this therapeutic strategy.

\section{ACKNOWLEDGMENT}

Nil.

\section{PROFORMA}

Code number:

Date of admission:

Age:

Date of Discharge:

Sex: Hospital number:

COVID RT-PCR:

Co-morbidities:

Severity of the illness at presentation (Based on clinical parameters): Mild/Moderate/Severe

Biomarkers:

First test Second test Third test Fourth test Fifth test

$\begin{array}{llll}\text { Day } 1 & \text { Day } 3 & \text { Day } 6 & \text { Day } 12\end{array}$

Serum ferritin

CRP

$\mathrm{LDH}$

D-dimer

Remdesivir: Not Received/Received

Oxygen requirement: Yes/No Number of days: Ventillator requirement: Yes/No Number of days:

Days of ICU stay:

Days of Hospital stay:

Condition at discharge:

\section{REFERENCES}

1. Zeng F, Huang Y, Guo Y, Yin M, Chen X, Xiao L, et al. Association of inflammatory markers with the severity of COVID-19: A metaanalysis. Int J Infect Dis. 2020;96:467-474.

https://doi.org/10.1016/j.ijid.2020.05.055

2. Hendaus MA. Remdesivir in the treatment of Coronavirus disease 2019(COVID-19): A simplified summary. J Biomol Struct Dyn. 2020;39(10):3787-3792. https://doi.org/10.1080/07391102.2020.1767691

3. Malik P, Patel U, Mehta D, Patel N, Kelkar R, Akrmah M, et al. Biomarkers and outcomes of COVID-19 hospitalisations: Systematic review and meta-analysis. BMJ Evid Based Med. 2021;26(3):107-108.

https://doi.org/10.1136/bmjebm-2020-111536

4. Mostaghim A, Sinha P, Bielick C, Knudsen S, Beeram I, White LF, et al. Clinical outcomes and inflammatory marker levels in patients with COVID-19 and obesity at an inner-city safety net hospital. PLoS One. 2020;15(12):e0243888.

https://doi.org/10.1371/journal.pone.0243888

5. Lee EE, Song KH, Hwang W, Ham SY, Jeong H, Kim JH, et al. Pattern of inflammatory immune response determines the clinical course and outcome of COVID-19: Unbiased clustering analysis. Sci Rep. 2021;11(1):8080.

https://doi.org/10.1038/s41598-021-87668-z

6. Gomez JM, Du-Fay-de-Lavallaz JM, Fugar S, Sarau A, Simmons JA, Clark B, et al. Sex differences in COVID-19 hospitalization and mortality. J Womens Health (Larchmt). 2021;30(5):646-653.

https://doi.org/10.1089/jwh.2020.8948

7. Bischof $\mathrm{E}$, Wolfe $\mathrm{J}$ and Klein SL. Clinical trials for COVID-19 should include sex as a variable. J Clin Invest. 2020;130(7):3350-3352.

https://doi.org/10.1172/jci139306

8. Beigel JH, Tomashek KM, Dodd LE, Mehta AK, Zingman BS, Kalil AC, et al. Remdesivir for the treatment of COVID-19-final report. N Engl J Med. 2020;383(19):1813-1826.

https://doi.org/10.1056/nejmoa2007764

9. Mehta RM, Bansal S, Bysani S and Kalpakam H. Ashorter symptom onset to remdesivir treatment (SORT) interval is associated with a lower mortality in moderate-to-severe COVID-19: A real-world analysis. Int J Infect Dis. 2021;106:71-77.

https://doi.org/10.1016/j.ijid.2021.02.092

10. Ghahramani S, Tabrizi R, Lankarani KB, Kashani SM, Rezaei S, Zeidi $\mathrm{N}$, et al. Laboratory features of severe vs. non-severe COVID-19 patients in Asian populations: A systematic review and meta-analysis. Eur J Med Res. 2020;25(1):30.

https://doi.org/10.1186/s40001-020-00432-3

11. Black S, Kushner I and Samols D. C-reactive protein. J Biol Chem. 2004;279(47):48487-48490. https://doi.org/10.1074/jbc.r400025200

12. Liu F, Li L, Xu M, Wu J, Luo D, Zhu Y, et al. Prognostic value of interleukin-6, C-reactive protein, and procalcitonin in patients with COVID-19. J Clin Virol. 2020;127:104370.

https://doi.org/10.1016/j.jcv.2020.104370

13. Ali N. Elevated level of C-reactive protein may be an early marker to predict risk for severity of COVID-19. J Med Virol. 2020;92(11):2409-2411. https://doi.org/10.1002/jmv.26097

14. Mahat RK, Panda S, Rathore V, Swain S, Yadav L and Sah SP. The dynamics of inflammatory markers in Coronavirus disease-2019 (COVID-19) patients: A systematic review and meta-analysis. Clin Epidemiol Glob Health. 2021;11:100727. https://doi.org/10.1016/j.cegh.2021.100727

15. Smilowitz NR, Kunichoff D, Garshick M, Shah B, Pillinger M, Hochman JS, et al. C-reactive protein and clinical outcomes in patients with COVID-19. Eur Heart J. 2021;42(23):2270-2279. https://doi.org/10.1093/eurheartj/ehaa1103

16. Qu G, Huang G, Zhang M, Yu H, Song X, Zhu H, et al. Features of C-reactive protein in COVID-19 patients with different ages, clinical types and outcomes: A cohort study. bioRxiv. 
2020;2020:20220160.

https://doi.org/10.1101/2020.10.26.20220160

17. Gaffney PJ. Breakdown products of fibrin and fibrinogen: Molecular mechanisms and clinical implications. J Clin Pathol Suppl (R Coll Pathol). 1980;14:10-17.

https://doi.org/10.1136/jcp.33.suppl_14.10

18. He X, Yao F, Chen J, Wang Y, Fang X, Lin X, et al. The poor prognosis and influencing factors of high $\mathrm{D}$-dimer levels for COVID-19 patients. Sci Rep. 2021;11(1):1830.

https://doi.org/10.1038/s41598-021-81300-w

19. Paliogiannis P, Mangoni AA, Dettori P, Nasrallah GK, Pintus G and Zinellu A. D-dimer concentrations and COVID-19 severity: A systematic review and meta-analysis. Front Public Health. 2020;8:432.

https://doi.org/10.3389/fpubh.2020.00432

20. Huang Y, Lyu X, Li D, Wang L, Wang Y, Zou W, et al. A cohort study of 676 patients indicates D-dimer is a critical risk factor for the mortality of COVID-19. PLoS One. 2020;15(11):e0242045.

https://doi.org/10.1371/journal.pone.0242045

21. Hsu PP and Sabatini DM. Cancer cell metabolism: Warburg and beyond. Cell. 2008;134(5):703-707.

https://doi.org/10.1016/j.cell.2008.08.021
22. Henry BM, Aggarwal G, Wong J, Benoit S, Vikse J, Plebani M, et al. Lactate dehydrogenase levels predict coronavirus disease 2019 (COVID-19) severity and mortality: A pooled analysis. Am J Emerg Med. 2020;38(9):1722-1726.

https://doi.org/10.1016/j.ajem.2020.05.073

23. Carubbi F, Salvati L, Alunno A, Maggi F, Borghi E, Mariani R, et al. Ferritin is associated with the severity of lung involvement but not with worse prognosis in patients with COVID-19: Data from two Italian COVID-19 units. Sci Rep. 2021;11(1):4863. https://doi.org/10.1038/s41598-021-83831-8

24. Martha JW, Wibowo A, Pranata R. Prognostic value of elevated lactate dehydrogenase in patients with COVID-19: a systematic review and meta-analysis. Postgrad Med J. 2021 15:postgradmedj-2020-139542. https://doi.org/10.1136/postgradmedj-2020-139542

25. Zhou B, She J, Wang $Y$ and Ma X. Utility of ferritin, procalcitonin, and C-reactive protein in severe patients with 2019 novel Coronavirus disease. Res Sq. 2020. https://doi.org/10.21203/rs.3.rs-18079/v1

26. Onur ST, Altın S, Sokucu SN, Fikri Bi, Barça T, Bolat E, et al. Could ferritin level be an indicator of COVID-19 disease mortality? J Med Virol. 2021;93(3):1672-1677. https://doi.org/10.1002/jmv.26543

\section{Authors Contribution:}

SR-Concept and design of the study; data acquisition, prepared first and final draft of manuscript; DJ- Literature search, data acquisition, prepared first and final draft of manuscript; JCA- Concept and design of study, coordination, manuscript editing, and manuscript review; VBKP- Statistical analysis, manuscript editing, and manuscript review; EM- Literature search, data acquisition, and manuscript editing; SVSRP- Literature search, data acquisition, and manuscript editing.

Work attributed to:

Vydehi Institute of Medical Sciences and Research Centre, Bengaluru, Karnataka, India.

Orcid ID:

Sanjana Rai - (1) https://orcid.org/0000-0001-9191-3961

Dyna Jones - (D) https://orcid.org/0000-0002-5226-4214

Jayashankar Chinnappa Anjanappa - (1) https://orcid.org/0000-0002-7740-9301

Venkata Bharat Kumar Pinnelli - (D https://orcid.org/0000-0002-0492-410X

Eashwer Manpreeth - (1) https://orcid.org/0000-0001-8705-5706

Seetha Venkata Sai Raghava Prashanthi - (1) https://orcid.org/0000-0003-3567-9490

Source of Support: Nil, Conflict of Interest: None declared. 